\title{
Manifestación atípica de carcinoma renal de células claras. Reporte de un caso
}

\section{Atypical presentation of clear cell renal cell carcinoma. A case report}

\author{
Emilio de León-Castorena, ${ }^{1}$ Selene Daneyda Ramírez-Vallejo²
}

\begin{abstract}
Resumen
CASO CLínICO: Paciente masculino de 60 años que acudió al servicio médico por una neoformación de 3 meses de evolución, localizada en la región occipital del cuero cabelludo, dolorosa, con hipersensibilidad y sangrado fácil a la manipulación. A la exploración física se encontraron signos vitales normales. Se observó una tumoración esférica de $4 \times 4 \times 3 \mathrm{~cm}$ en la región occipital, eritematosa, bien delimitada, de bordes regulares, consistencia blanda, discretamente móvil, alopecia y costra serohemática en su centro, acompañada de dolor a la palpación. El diagnóstico sugerente fue quiste triquilemal o pilar; sin embargo, el ultrasonido evidenció una tumoración sólida, de ecogenicidad heterogénea, vascularizada al doppler. El estudio histopatológico reportó una neoplasia con patrón morfológico compatible con metástasis por carcinoma renal de células claras. En el posoperatorio, la tomografía evidenció la coexistencia de una neoplasia en el riñón derecho, con características radiológicas de carcinoma de células claras en etapa IV (T4N1M1) y múltiples lesiones nodulares sólidas compatibles con metástasis parenquimatosa pulmonar bilateral. El paciente se valoró con enfermedad renal terminal y decidió descontinuar su tratamiento; se observó deterioro importante en el estado general y falleció poco tiempo después por enfermedad metastásica diseminada.

CONCLUSIONES: La metástasis al cuero cabelludo puede simular un quiste triquilemal y acompañarse de alopecia neoplásica. Las metástasis cutáneas de carcinoma de células claras son difíciles de identificar, pues se asemejan a las dermatosis comunes, por lo que su índice de sospecha es bajo y representan un signo de mal pronóstico, pues sugieren afectación multiorgánica.
\end{abstract}

PALABRAS CLAVES: Carcinoma de células renales; metástasis cutánea.

\section{Abstract}

CLINICAL CASE: A 60-year-old man sought medical attention for a painful, hypersensitive neoformation of 3-month progression located at the occipital region of the scalp, that bled easily upon manipulation. Physical examination revealed normal vital signs. A 4 x 4 × 3 -cm soft, erythematous, slightly mobile, well-defined sphere-shaped tumor was observed at the occipital region, with alopecia. It had regular edges and a serohematic scab at its center and was painful upon palpation. The lesion was suggestive of a trichilemmal or pilar cyst, but ultrasound study identified a solid tumor with heterogeneous echogenicity and Doppler imaging showed vascularization. The histopathologic report stated neoplasia with a morphologic pattern consistent with metastatic clear cell renal cell carcinoma. Postoperative tomography showed the coexistence of a tumor in the right kidney, with radiologic characteristics of stage IV clear cell renal cell carcinoma (T4N1M1) and multiple solid nodular lesions consistent with bilateral pulmonary parenchymal metastasis. The patient developed end-stage renal disease and decided to discontinue treatment. He had important deterioration in his general state of health and died shortly thereafter from disseminated metastatic disease.

CONCLUSIONS: Metastasis to the scalp can simulate a trichilemmal cyst and be accompanied by neoplastic alopecia. Cutaneous metastases from clear cell renal cell carcinoma are difficult to identify because they resemble common dermatoses, resulting in a low rate of suspicion. They are a sign of poor prognosis, given that they suggest the involvement of multiple organs.

KEYWORDS: Clear cell renal cell carcinoma; Metastasis; Cutaneous.

\footnotetext{
Departamento de Cirugía general. 2 Departamento de Anatomía patológica.
}

Universidad Autónoma de Coahuila, Hospital Universitario de Torreón Dr. Joaquín del Valle Sánchez.

Recibido: diciembre 2017

Aceptado: mayo 2018

Correspondencia

Emilio de León Castorena

edeleoncastorena@gmail.com

Este artículo debe citarse como de León-Castorena E, Ramírez-Vallejo SD. Manifestación atípica de carcinoma renal de células claras. Reporte de un caso. Rev Mex Urol. 2018 mayojunio;78(3):220-224.

DOI:https://doi.org/10.24245/revmexurol.v78i3.1641 


\section{ANTECEDENTES}

El carcinoma de células renales es la tercera neoplasia más común del aparato genitourinario. Es el tumor renal maligno más frecuente y corresponde a $3 \%$ de las neoplasias malignas sólidas en el paciente adulto. ${ }^{1-4}$ En México representa $1.5 \%$ de todos los tumores. ${ }^{4}$ Solo $10 \%$ de los casos de cáncer renal inician con la triada de Guyon (hematuria, dolor en flanco y masa palpable) ${ }^{5}$ haciendo a esta clínica patognomónica, la excepción más que la regla. ${ }^{6}$ Algunos estudios señalan que más de $40 \%$ de los pacientes no manifiesta síntomas genitourinarios ${ }^{7}$ y $30 \%$ evoluciona a metástasis al momento del diagnóstico. ${ }^{8,9}$ Una tercera parte de los pacientes con carcinoma de células renales fallece por la enfermedad; por tanto, representa el tumor renal con mayor tasa de mortalidad. ${ }^{3}$ El carcinoma de células claras es el subtipo más común del carcinoma de células renales, incluso afecta a $60 \%$ de los casos..$^{10}$ En el contexto de metástasis a distancia por tumores urológicos, la incidencia de metástasis cutánea es baja, por lo que es importante su análisis.

\section{CASO CLÍNICO}

Paciente masculino de 60 años, obeso, con antecedente de tabaquismo intenso por 17 años e hipertensión arterial primaria (en tratamiento con metoprolol). Acudió al servicio médico por una neoformación de 3 meses de evolución, localizada en la región occipital del cuero cabelludo, dolorosa, con hipersensibilidad y sangrado fácil a la manipulación, pero que cedía a la compresión. Refirió episodio único y aislado de hematuria macroscópica 5 años atrás, que se curó con AINES por vía oral. Negó síntomas urinarios irritativos u obstructivos, pérdida ponderal, dolor en el flanco o fiebre. A la exploración física se encontraron signos vitales normales. Se observó un paciente obeso, con tumoración esférica de $4 \times 4 \times 3 \mathrm{~cm}$ en la región occipital, eritematosa, bien delimitada, de bordes regulares, consistencia blanda, discretamente móvil, alopecia y costra serohemática en su centro, acompañada de dolor a la palpación (Figura 1A). El diagnóstico sugerente fue quiste triquilemal o pilar, por lo que se solicitó un ultrasonido que evidenció una tumoración sólida, de ecogenicidad heterogénea, vascularizada al doppler. Los estudios de laboratorio reportaron anemia e hipercalcemia leves y concentraciones elevadas de fosfatasa alcalina y azoados. El examen general de orina resultó sin datos patológicos; la concentración de albúmina, PT, LDH y tiempos de coagulación estuvieron dentro de los parámetros normales. Para el estudio histopatológico se efectuó una biopsia excisional (Figura 1B y 1C) que reportó: neoplasia con patrón morfológico compatible con metástasis por carcinoma renal de células claras, con márgenes quirúrgicos libres (Figura 2). En el posoperatorio se solicitó una tomografía computada simple y con contraste de abdomen, que comprobó la coexistencia de la neoplasia en el riñón derecho, con características radiológicas de carcinoma de células claras en etapa IV (T4N1M1) (Figura 3) y múltiples lesiones nodulares sólidas compatibles con metástasis parenquimatosa pulmonar bilateral. El paciente fue enviado al servicio de Oncología quirúrgica, donde identificaron una lesión nodular subcutánea en la cara anterior del pectoral izquierdo. Se inició terapia sistémica neoadyuvante con pazopanib. Poco después de haber iniciado el tratamiento acudió, en múltiples ocasiones, al servicio de Urgencias por cólico nefrítico. El ultrasonido de vías urinarias evidenció nefrocalcinosis derecha y litiasis renal ipsilateral, que provocaba hidronefrosis leve. En el servició de Urología se valoró para control del dolor y egresó por mejoría clínica. Durante el seguimiento oncológico se observó disminución del tamaño de la lesión nodular en el tórax. La tomografía de control mostró, en la zona pulmonar, disminución importante del tamaño de las metástasis. En el riñón se observó mínima 


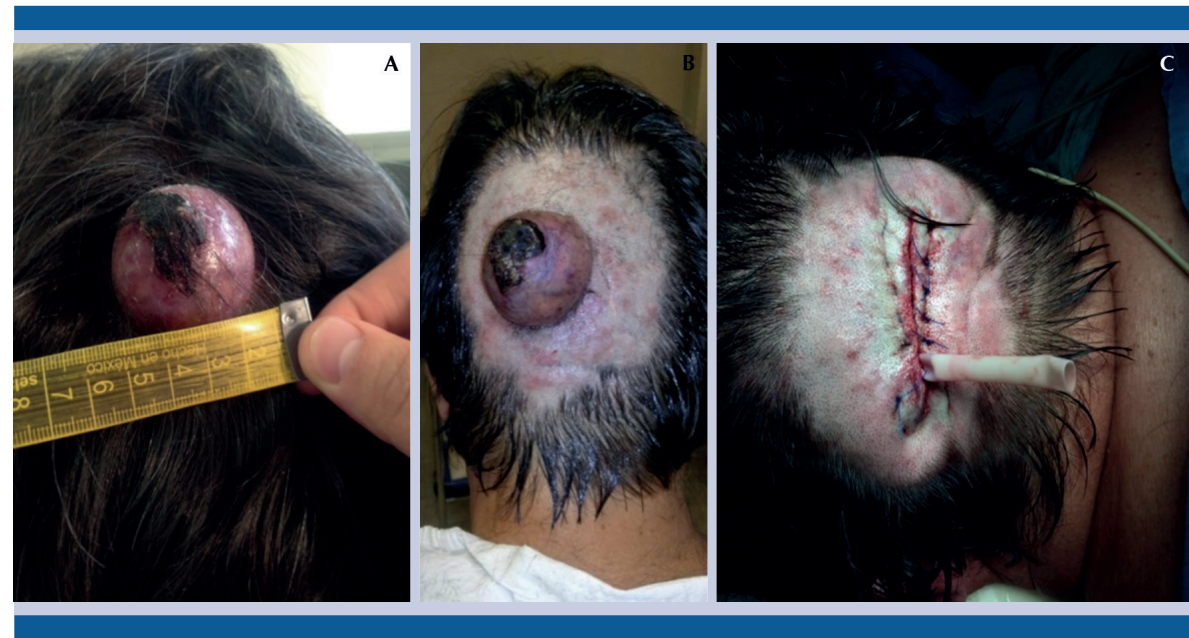

Figura 1. (A) Tumoración esférica en la región occipital, eritematosa, alopécica, bien delimitada, con bordes regulares, de consistencia blanda, discretamente móvil y costra serohemática en su ápice. (B y C) Lesión en el perioperatorio.

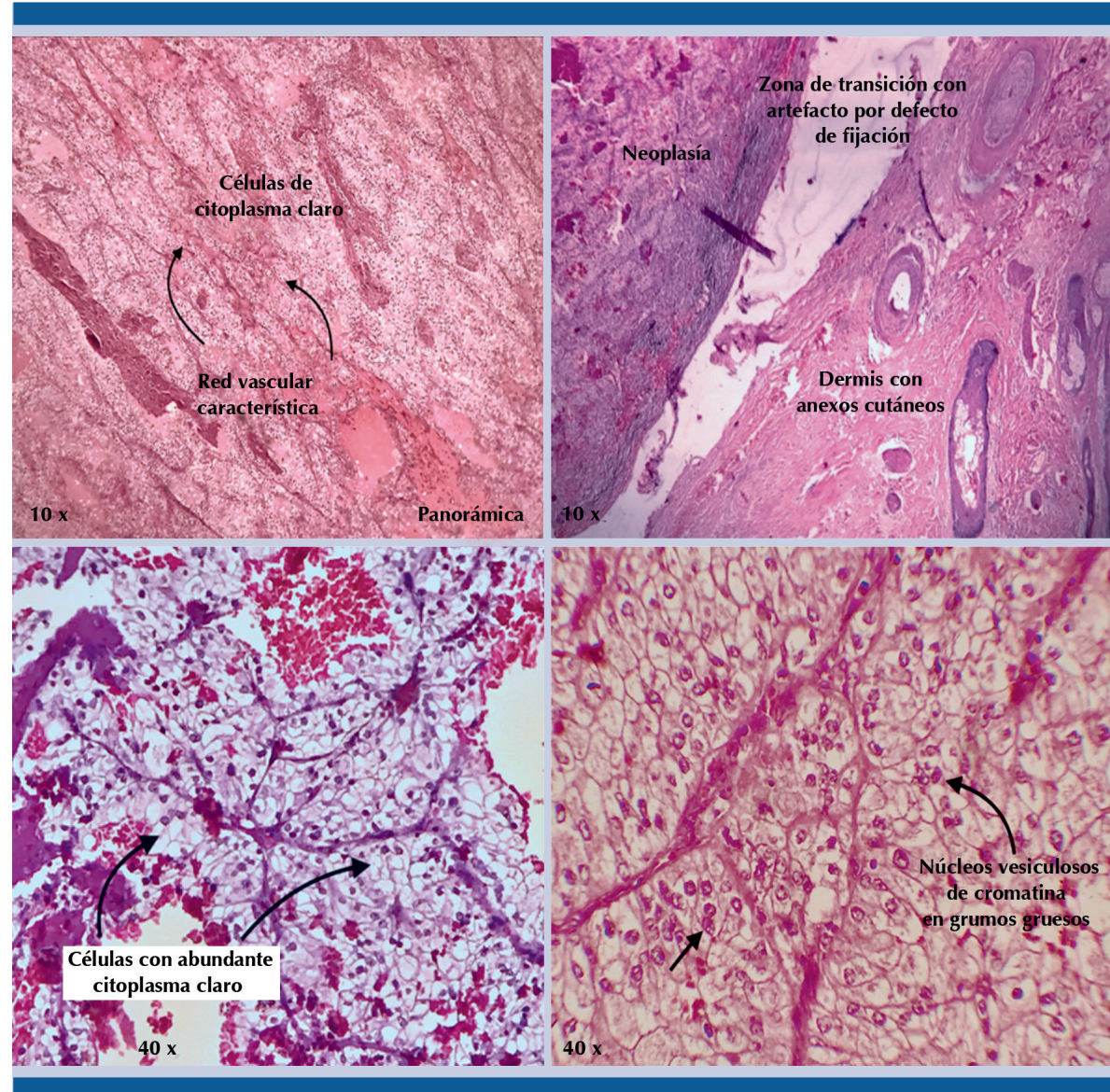

Figura 2. Características histopatológicas con patrón morfológico compatible con metástasis por carcinoma renal de células claras. 
reducción de las dimensiones del tumor, además de litiasis renal no obstructiva contralateral. El paciente se valoró con enfermedad renal terminal y decidió descontinuar su tratamiento; se observó deterioro importante del estado general y falleció poco tiempo después por enfermedad metastásica diseminada.

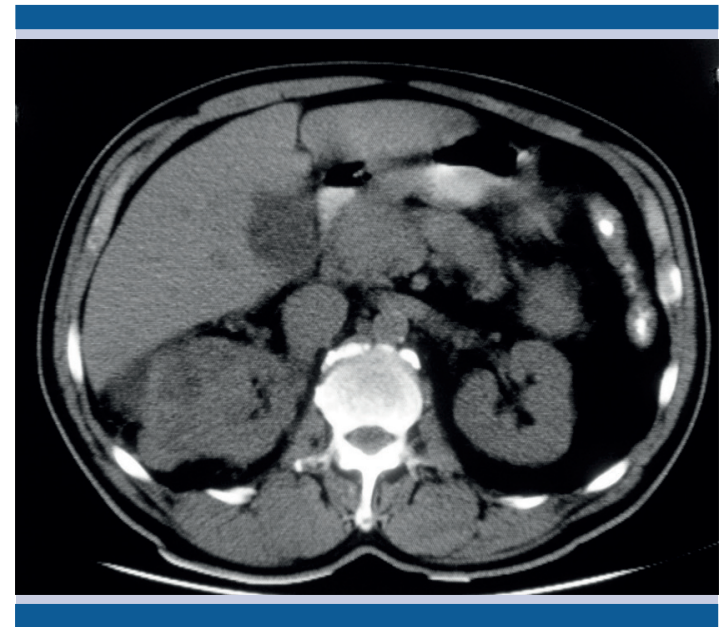

Figura 3. Tomografia abdominal que muestra la neoplasia renal derecha con áreas de necrosis, signos de invasión hacia la grasa perirrenal y glándula suprarrenal correspondiente. Adenomegalias mesentéricas y retroperitoneales múltiples de tipo metastásico.

\section{DISCUSIÓN}

Las metástasis cutáneas aparecen en 0.7-9\% de los pacientes con cáncer. ${ }^{2}$ Raramente se expresan al momento del diagnóstico (1.3\%) y solo constituyen el motivo de consulta en $0.8 \%$ de los casos. ${ }^{11}$ Los tumores renales son responsables de 3-6\% de las metástasis cutáneas. ${ }^{1,2,11}$ Las metástasis cutáneas provocadas por tumores malignos urológicos son manifestaciones poco comunes de enfermedad avanzada (1\%), ${ }^{2}$ que afectan frecuentemente a los hombres. ${ }^{12,13}$ Este dato puede explicarse, quizá porque el cáncer pulmonar y renal son comunes en el sexo masculino y tienden a evolucionar a metástasis de forma temprana. ${ }^{14}$ La metástasis al cuero cabelludo puede originarse por diversos tipos de cáncer: en hombres aparece por tumores primarios que tienden a invadir las venas (cáncer de pulmón o riñón) y en mujeres se observa en etapas tardías del cáncer de mama. ${ }^{12,15}$ También en los hombres, las metástasis cutáneas por tumores genitourinarios afectan frecuentemente el abdomen, ${ }^{15,16}$ pero en el contexto de carcinoma de células renales suelen aparecer en la cabeza y el cuero cabelludo, seguido del tórax y la región abdominal. ${ }^{1,12,17}$ La metástasis al cuero cabelludo puede simular un quiste triquilemal y acompañarse de alopecia neoplásica, ${ }^{15}$ como lo sugirió el diagnóstico del paciente de este estudio. Las metástasis cutáneas de carcinoma de células claras tienen apariencia típica, suelen manifestarse como un nódulo solitario o múltiple, vascularizado, doloroso o indoloro, que puede sangrar con facilidad. ${ }^{17,18}$ La escisión quirúrgica representa un tratamiento útil en pacientes con metástasis cutáneas. ${ }^{19}$ En sujetos con carcinoma renal de células claras se observa una histología característica, compuesta por células con abundante citoplasma claro, red vascular distintiva y núcleos vesiculosos de cromatina con grumos gruesos. ${ }^{20}$ Histológicamente, las metástasis cutáneas suelen afectar la dermis y, a veces, se extienden hacia el tejido subcutáneo. ${ }^{2}$ Las metástasis cutáneas de carcinoma de células claras son difíciles de identificar, pues se asemejan a las dermatosis comunes, por lo que su índice de sospecha es bajo. ${ }^{2}$ Desafortunadamente, los casos de metástasis cutáneas de carcinoma de células claras representan un signo de mal pronóstico, porque sugieren afección multiorgánica. ${ }^{2,14,21} \mathrm{En}$ estos pacientes el tratamiento debe estar enfocado en términos paliativos. ${ }^{22}$ La supervivencia en sujetos con carcinoma de células claras se relaciona directamente con el estadio clínico al momento del diagnóstico. Los pacientes que manifiestan síntomas suelen tener un estadio más avanzado que quienes los expresan de manera fortuita. En pacientes con carcinoma de células renales avanzado (T4) se estima una 
supervivencia de 13 meses (la supervivencia a 5 años es menor a 10\%); ${ }^{23}$ sin embargo, en quienes padecen metástasis cutánea de reciente aparición, la supervivencia estimada es menor de 6 meses. ${ }^{2}$ Puesto que las lesiones dermatológicas de reciente aparición, similares a las dermatosis comunes, pueden representar marcadores de malignidad interna, es importante realizar la evaluación clínico-anatomopatológica, así como el interrogatorio médico. Solamente la detección y estadificación del cáncer subyacente puede ofrecer un pronóstico y tratamiento más certero.

\section{Conflicto de intereses}

Los autores declaran no tener conflictos de interés.

\section{REFERENCIAS}

1. Rongioletti F, Margaritescu I, Smoller BR. Rare malignant skin tumors. New York: Springer, 2014. doi: 10.1007/9781-4939-2023-5_74

2. Mueller TJ, Wu H, Greenberg RE, Hudes G, et al. Cutaneous metastases from genitourinary malignancies. Urology 2004;63(6):1021-1026. doi: https://doi.org/10.1016/j. urology.2004.01.014

3. Wein A, Kavoussi L, Partin A, Peters C. Campbell-Walsh Urology. $11^{\text {th }}$ ed. Philadelphia Elsevier, 2016;1320.

4. Acosta-Jiménez $E$, Jerónimo-Guerrero $D$, Macías-Clavijo MA, Rivera-Diez D, et al. Carcinoma de células renales: factores patológicos pronósticos, estadificación y clasificación histopatológica. Rev Med Inst Mex Seguro Soc 2015;53(4):454-65.

5. Cairns P. Renal cell carcinoma. Cancer Biomark 2010;9(16):461-73. doi: 10.3233/cbm-2011-0176

6. Sountoulides P, Metaxa L, Cindolo L. Atypical presentations and rare metastatic sites of renal cell carcinoma: a review of case reports. J Med Case Rep 2011;5:429-429. doi: 10.1186/1752-1947-5-429

7. Gibbons RP, Monte JE, Correa RJ, Mason JT. Manifestations of renal cell carcinoma. Urology 1976;8(3):201-6.
8. Ather MH, Masood N, Siddiqui T. Current management of advanced and metastatic renal cell carcinoma. Urol J 2010;7(1):1-9.

9. Navarrete-Gutiérrez G, Fuentes-Valencia A, SalaverríaCáceres J, Vela-Jiménez G. Metástasis al cuero cabelludo de carcinoma de células claras. Actas Urol Esp 2010;34:923924.

10. Paula TA, Silva L, Berriel LG. Carcinoma de células renais com metástase cutânea: relato de caso. J Bras Nefrol 2010;32:213-215

11. Lookingbill DP, Spangler N, Sexton F. Skin involvement as the presenting sign of internal carcinoma: A retrospective study of 7316 cancer patients. J Am Acad Dermatol 1990;22(1):19-26.

12. Brownstein $\mathrm{MH}$, Helwig EB. Metastatic tumors of the skin. Cancer 1972;29(5):1298-307.

13. Dorairajan LN, Hemal AK, Aron M, Rajeev TP, et al. Cutaneous metastases in renal cell carcinoma. Urol Int 1999;63(3):164-7.

14. Hanson RP, Kneafsey B, Royston D. Cutaneous lesions, not just skin deep! Ir J Med Sci 2006;175(1):66-8.

15. Thiers BH. Dermatologic manifestations of internal cancer. CA Cancer J Clin 1986;36(3):130-148. doi: 10.3322/ canjclin.36.3.130

16. Held B, Johnson DE. Cutaneous metastases from malignant genitourinary disease. South Med J 1972;65(5):569-71. doi: 10.1097/00007611-197205000-00012

17. Rolz-Cruz G, Kim CC. Tumor invasion of the skin. Dermatol Clin 2008;26(1):89-102.

18. Ahmad A, Wu K, Tan W. Renal cell carcinoma with skin metastasis: A case report and literature review. Cancer Clin Oncol 2013;2(1). doi: 10.5539/cco.v2n1p80

19. Martínez L, Vilata Corell JJ. Metástasis cutáneas de neoplasias internas. Med Cutan Iber Lat Am 2009;37(3):117-129.

20. López JI, Ugalde A, Zhou M. Carcinomas renales con células claras. Rev Esp Patol 2008;41(3):169-182. doi: 10.1016/ S1699-8855(08)70118-1

21. Fernández P, Ruiz P, Ramirez MA, et al. Metástasis cutánea de carcinoma de células renales (MCCCR): reporte de caso y revisión de la literatura. Gac Med Mex 2015;151(4):533537.

22. Espósito D, Chiappe C, Sánchez G, et al. Metástasis cutáneas de adenocarcinoma renal. Arch Argent Dermatol 2016;66(4):113-117.

23. Cohen HT, McGovern FJ. Renal-cell carcinoma. NEJM 2005;353(23):2477-2490. doi: 10.1056/NEJMra043172 